\title{
Entre lo salvaje y la inocencia: lectura intertextual de La Vorágine y El abrazo de la Serpiente*
}

\section{Resumen}

El presente artículo de reflexión tiene como propósito sugerir una nueva mirada sobre algunas narrativas que involucran la representación del indígena, y la compleja realidad que lo define mediante un análisis intertextual entre la obra literaria La Vorágine (1924) de José Eustasio Rivera y la película El Abrazo de la Serpiente dirigida por Ciro Guerra (2015). La investigación permite determinar que tanto la obra literaria como la película resignifican el papel del indígena en relación con la categoría de inocencia, como característica propia de esta comunidad. Así mismo, posibilitan una nueva lectura de algunos acontecimientos de la historia colombiana.

Palabras clave: indígena, infancia, inocencia, intertextualidad, novela, película, relato, selva amazónica.
Citar: Cubides, Edwin \& Garay, Luz. "Entre lo salvaje y la inocencia: lectura intertextual de La Vorágine y El abrazo de la Serpiente". La Palabra, núm.40, 2021,e11630. https://10.19053/01218530.n40.2021.11630

\section{Edwin Cubides Serrano}

Doctorando en ciencias humanas y profesor de literatura de la Universidad Santo Tomás.

edwincubides@ustadistancia. edu.co.

(iDhttps://orcid.org/0000-00015298-9250

\section{Luz Adriana Garay Cano}

Estudiante de pregrado en literatura de la Universidad Santo Tomás.

luzgaray@ustadistancia.edu.co

(Dhttps://orcid.org/0000-00016462-0207

*Artículo de reflexión.

Este texto es producto del semillero de investigación Sincretismos, en su línea de investigación "Voces de infancia: Narrativas y prácticas estéticas en torno a la infancia" de la licenciatura en Literatura y Lengua Castellana. 


\section{Simplicity and savage in La Vorágine [The Vortex] and El abrazo de la serpiente [Embrace of the Serpent]}

\section{Abstract}

This paper aims a new approach to indigenous representation in literature and cinema through the intertextual analysis between La Vorágine (1924) [The Vortex] and El abrazo de la serpiente (2015) [Embrace of the Serpent]. It is concluded, after a detailed study, that both - the novel and the film, bring a new perspective from the indigenous by means of simplicity as an actual way of being of this important community in Colombia.

Key words: indigenous, childhood, simplicity, intertextuality, novel, film, plot, Amazon

\section{Entre o selvagem e a inocência: leitura intertextual de La Vorágine e $E l$ abrazo de la Serpiente}

\section{Resumo}

O presente artigo tem como objetivo desenvolver um novo olhar sobre algumas narrativas que envolvem a representação do indígena e da complexa realidade que o define por meio da análise intertextual entre a obra literária La Vorágine (1924) de José Eustasio Rivera e o filme El Abrazo de la Serpiente dirigido por Ciro Guerra (2015). A pesquisa possibilita determinar como tanto a obra literária quanto o filme resignificam o papel do indígena em relação com a categoria de inocência como característica própria. Assim mesmo, permite uma nova leitura de alguns acontecimentos da história colombiana.

Palavras-chave: indígena, infância, intertextualidade, romance, filme, relato, floresta amazônica. 


\section{Oh, selva, esposa del silencio, madre de la soledad y la neblina! ¿Qué hado maligno me dejó prisionero en tu cárcel verde?}

Arturo Cova. La Vorágine

\section{Introducción}

En la presentación de la novela La vorágine, publicación que se incorpora a la colección Biblioteca básica de cultura colombiana de la Biblioteca Nacional de Colombia, Antonio Caballero anuncia que la gran novela de Colombia es La vorágine, de José Eustasio Rivera, pues todo cabe en ella, no solo la «denuncia periodística de los horrores del genocidio de los indios y la explotación de los caucheros por la famosa Casa Arana» (Rivera 8), sino, también, la fijación hacia rasgos negativos opuestos a cualquier idealización del indígena (Orrego 37). A pesar de ello, gran parte de la crítica en torno a la obra de Rivera sitúa el lugar y la presentación del indígena en la obra como ladrón, mentiroso y grosero (Alzate, Restrepo y Osorio) y ha dejado de lado una posible lectura que no parte necesariamente de la postura de Arturo Cova, sino de voces indirectas que muestran al indígena entre la pérdida y la inocencia.

Esta inocencia es una de las características predominantes, pero silenciadas en las tribus indígenas, aparece en La vorágine descrita como: «La mansedumbre le prepara terreno a la tiranía y la pasividad de los explotados sirve de incentivo a la explotación. Su bondad y su timidez han sido cómplices inconscientes de sus victimarios» (Rivera, 238). Esta inocencia es también visible como potencia en El abrazo de la serpiente, relato en el que las nuevas dinámicas impuestas por los conquistadores reconfiguraron las relaciones sociales establecidas en el territorio americano, y en el que se imponen nuevos criterios de correlación de los nativos con la naturaleza, los dioses, los explotadores y entre ellos mismos. Se intentará mostrar cómo esta categoría de inocencia como potencia la representan a través del lenguaje literario y cinematográfico José Eustasio Rivera y Ciro Guerra, respectivamente.

\section{La otra mirada sobre el continente}

Indudablemente, el evento americano ${ }^{1}$ determina un cambio radical en las relaciones sociales y políticas mundiales, reconfigurando las relaciones económicas y epistémicas de los dos mundos. En esta historia de sometimiento del indígena, el relato sobre este ha jugado un papel importante, articulando lo letrado a la organización estatal: «el Estado colonial supone una articulación de las figuras despóticas y de los aparatos de captura del conquistador y del conquistado que hacen posible la obediencia, la disciplina y la articulación entre las distintas máquinas sociales» (Chaparro Amaya 194).

En dicho contexto, podríamos decir que las plantaciones de caucho en el Amazonas, en la llamada fiebre del caucho, constituye una de estas articulaciones de los aparatos de captu-

Rita Segato, en varias de sus clases y conferencias, renombra a lo que históricamente se ha denominado descubrimiento de América como "El evento americano", en el sentido de resignificar la experiencia histórica del acontecimiento del encuentro de dos mundos y su posterior colonización, sometimiento y esclavización de lo indígena por lo europeo (Facultad Libre, 2016). 
ra que prolonga las dinámicas esclavistas impuestas. La extracción y comercio del caucho, al igual que la ambición europea, cobró múltiples vidas e impuso el terror como dinámica social.

La Casa Arana fue una compañía que llegó al Putumayo en 1899, su principal actividad fue la extracción y comercialización de caucho por medio de la esclavitud indígena: «El señor Arana ha formado una compañía que es dueña de los cauchales La Chorrera y los de El En- canto. ¡Hay que trabajar, hay que ser sumisos, hay que obedecer!» (Rivera 198). En esta compañía, los miembros de las comunidades indígenas eran obligados a trabajar mediante un sistema de endeude cumpliendo tareas que no se limitaban a la actividad cauchera: «ese pastuso sin corazón, socio de Arana y otros peruanos que en la hoya amazónica han esclavizado más de treinta mil indios» (Rivera, 196) y que constituyeron todo un sistema de esclavitud en la Amazonía ${ }^{2}$. Este sistema transformó las dinámicas sociales de los nativos, pues eran obligados a realizar actividades de caza y construcción; las mujeres eran sexualmente abusadas y comercializadas; los niños eran sometidos a trabajos forzados bajo precarias condiciones $\mathrm{y}$, cuando los extractores consideraban necesario, torturaban y acribillaban de manera atroz al pueblo indígena.

a veces se aplicaba agua y sal sobre las heridas, pero, en muchos casos, no se hacía ni siquiera este miserable esfuerzo de curación tras una flagelación fatal y la víctima "con gusanos en la carne" era desviada en el bosque para morir o se le disparaba y el cuerpo era quemado o enterrado o, a menudo, arrojado en el "monte" cerca a las casas de la estación. (caaap y iwgia 95)

Quizás fue La vorágine uno de los textos más importantes que reflejó, desde el relato, los sucesos en el contexto de la fiebre del caucho y que, desde la voz de Arturo Cova, contribuyó a fortalecer la mirada taxonómica sobre la categoría de persona que ponía al indígena más cerca de lo animal que de lo humano. Como bien lo menciona Uscátegui Narváez:

La representación del indígena en la historia de la literatura latinoamericana ha sido porosa, ha existido la urgencia por reconocer la heterogeneidad cultural, sin embargo, parece ser que la mirada exotista no desampara aquellos registros, en busca del esteticismo que legitima sus valores literarios. (229)

En esta representación se configura el dispositivo de la persona. Roberto Espósito (2009a) argumenta de manera clara, cómo la categoría de persona es la que produce el hiato o la conjunción entre vida y derecho y que, al lado de esta configuración, el derecho romano establece una serie de grados o niveles que pasan por la casi-persona (en el que es posible insertar la figura del infante), del animal y la cosa; que son los que de una u otra forma separan,

Sobre La vorágine como una novela de relatos, Benso presenta una interesante aproximación a los distintos relatos que se construyen en la obra, teniendo en cuenta el trabajo realizado por Joan R. Green. Los distintos narradores de la obra permiten un juego de variedad de aproximaciones a lo diegético, y en ese sentido: «El panorama social no aparece con estructura propia sino más bien como una especie de mosaico» (Benso, 1975, p. 290). Vemos este mosaico, en alguna medida, en la obra de Guerra, que indudablemente también juega con la posibilidad del relato al construir los motivos fundamentales de los viajes de los antropólogos: el relato sobre una planta (sobre la naturaleza) y el libro del primer viajero que será el motivo para el segundo viaje. 
organizan y jerarquizan las relaciones sociales y políticas en los extremos de lo racional y lo irracional. Cada una de esas gradaciones podría o no tener aquellos niveles de racionalidad que lo harían entrar o no en esta categoría. Estas formas de vida son actualizadas, resignificadas y revalorizadas en los relatos contemporáneos en los que se recuperan aquellas voces que fueron llevadas hacia el lugar de lo irracional y que, por ejemplo, en la narración cinematográfica de Ciro Guerra, se ven dotadas de distintas complejidades que actualizan el debate sobre la representación del indígena:

[...] se va perfilando Karamakate, el único indígena rebelde a la explotación y alienación de la civilización occidental, el cual hace las veces de guía y chamán desde su temprana juventud, en primer lugar con el etnólogo alemán, y, luego, al pasar cuarenta años, ya en su plena madurez vuelve y sirve de guía, en su viaje iniciático, al biólogo gringo, en la iniciación del abrazo de la serpiente. (Marín Baena 455)

La irrupción de un nuevo relato sobre el indígena en la explotación cauchera tiene una característica interesante y es, en algunos momentos, la exposición de un rasgo de inocencia que, como define Sanmartín, se resignifica y genera una potencia desde los mismos rasgos minimizados, invisibilizados y negados:

En todas esas imágenes de la inocencia consta como idea matriz la preservación del sujeto a salvo del mal a pesar de su menor fuerza, de su escaso poder. [...] Sus limitaciones por la edad, discapacidad o pobreza, aun siendo marcas de contingencia y fragilidad, de daños o impotencia, refuerzan, como un oxímoron vital, la grandeza de su pequeñez, el lado positivo de su negatividad, el bien que encierra su limitación. (Sanmartín 146)

De esta manera, en La Vorágine se determina dicha característica a través de las relaciones del indígena con su medio; la inocencia se plantea desde las diversas voces narrativas que allí convergen. Helí Mesa (personaje de Rivera) enfatiza en el tráfico de hombres [en su mayoría indígenas] a través de los ríos Meta, Vichada y Guaviare. En su narración sobresale la inocencia de los caucheros frente a los engaños de los extractivistas, quienes se sirven de artimañas para persuadirlos y someterlos:

Aprovechando la borrachera que nos vencía, nos filiaba el Palomo y nos amarraba de dos en dos. Desde ese día fuimos esclavos y en ninguna parte nos dejaban desembarcar. Tirábannos el mañoco en unas coyabras, y, arrodillados, lo comíamos por parejas, como perros en yunta, metiendo la cara en las vasijas, porque nuestras manos iban atadas. (Rivera 161)

Lo que se ve aquí, en relación con el relato, es una experiencia que supera la voz de Mesa e irrumpe el relato. En este sentido, siguiendo a Sanmartín, ocurre con la inocencia algo peculiar y es que invade en la conciencia de los actores a partir de la experiencia de su pérdida — sobre todo de su pérdida traumática—; de ahí que se tenga que analizar esa experiencia para entender su sentido, y se hará atendiendo a las palabras con las que la describen.

En relación con lo anterior, en El abrazo de la serpiente, Manduca, ex esclavo de una plantación peruana, sufre un trastorno emocional [pérdida traumática] frente al encuentro 
con un indígena cauchero; pues se reconoce en la crudeza de dicha realidad y contempla el asesinato (el indígena suplicaba morir), simbolizando el fin de la realidad cauchera, el fin de su propio pasado. La experiencia traumática sobre la pérdida es la que permite establecer el relato de su propio pasado. Así mismo, en los dos personajes señalados anteriormente, ambas figuras indígenas, sobresale la descripción de la inocencia, relacionada a su vez con la sensación de miedo, la cual genera la necesidad de hablar sobre ello; en palabras de Sanmartín:

Apunta a una realidad antropológica indudable, es más, su valoración nos habla de la importancia que posee como condensación clave de cuanto nos constituye como hombres, de ese suelo humano al que llega el daño y que, como fondo, queda a salvo del mal, misteriosamente intacto y en el que se apoya toda esperanza, en el que nace la fuerza de toda creatividad. (1497)

Otro aspecto que refleja la complejidad del indígena y que supera su representación como salvaje es el método de endeude impuesto por los extractores para perpetuar su dinámica. En las descripciones de este, se resalta el carácter de inocencia de los trabajadores; puesto que dentro de sus propias tradiciones no concebían dichos artificios. El endeude era el mecanismo mediante el cual el empresario vinculaba al indígena a la práctica cauchera, en el que este último adquiría una deuda desde el inicio, que iba solventando con su mano de obra. Asimismo, dicha deuda se iba ampliando por conceptos de alimentación, vestimenta, herramientas y vivienda que, aunque de ninguna manera eran dignas, sí representaban un soporte monetario que los obligaba a continuar laborando para la compañía o en el intento de salir de ella, perder la vida:

El personal de trabajadores está compuesto, en su mayor parte, de indígenas y enganchados, quienes, según las leyes de la región, no pueden cambiar de dueño antes de dos años. Cada individuo tiene una cuenta en la que se le cargan las baratijas que le avanzan, las herramientas, los alimentos, y se le abona el caucho a un precio irrisorio que el amo señala. Jamás cauchero alguno sabe cuánto le cuesta lo que recibe ni cuánto le abonan por lo que entrega, pues la mira del empresario está en guardar el modo de ser siempre acreedor. Esta nueva especie de esclavitud vence la vida de los hombres y es transmisible a sus herederos. (Rivera 192)

Esta noción de deuda no es posible entenderla únicamente en términos físicos, sino también como el carácter fundante de la comunidad en la tradición occidental: «La ley de la comunidad no es otra que la comunidad de la ley, de la deuda, de la culpa [...] aquello que perdemos y que nunca hemos tenido» (Espósito 27). Esta comunidad que describe Espósito no es la de los indígenas, pues la suya es también aquella que ha asumido la carencia, como bien lo refiere Gaspar, el misionero de El abrazo de la serpiente:

\section{GASPAR}

¡Suéltame! ¡Ustedes trajeron al Diablo a la comunidad! ¡Ustedes pervierten a los inocentes! (Guerra y Toulemonde 72)

Ese común también podemos comprenderlo en el sentido en el que lo entiende Alejandra Marín, en su reflexión sobre la obra de Agamben, como el espacio que queda de la deuda 
pagada, como la carencia y el vacío también en el lenguaje y en el relato. Marín observa las relaciones entre lo que no está (la ausencia de habla) y lo común como una comunidad vacía carente de reglas y sin gramática (como la infancia):

Así, entre la pura desarticulación y el discurso codificado hay un salto, un salto en el que se juega el poder hablar. Por eso, la infancia, como experimentum linguae debe ser comprendida como un juego con la pura facultad vacía, desarticulada, carente de contenidos y de reglas, sin gramática. En esta posibilidad se juega una nueva idea de comunidad que es, como tal, una comunidad vacía. (Marín 8-9)

Precisamente por ello, es por lo que, en el mismo Abrazo de la serpiente, en la escena anterior del castigo del monje a los niños por la contaminación a la comunidad [a esa otra comunidad] es preciso ejemplificar el carácter complejo del indígena. La inocencia perdida a la que hace referencia el cura no es la inocencia de la infancia, como condición de lo huma$n^{3}$. Posteriormente, como se observa en el guión de la película, la indeterminación que se presenta en el desconocimiento de qué hacer, del futuro, remarca ese carácter de lo inocente, que también es ausencia de conocimiento:

\section{KARAMAKATE}

Huyan.

Intercambia una mirada con el niño 2. La expresión de éste muestra una mezcla de resentimiento y de temor. Karamakate corre hacia el muelle. Los niños se quedan quietos, alterados todavía, mientras sus compañeros los rodean. (Guerra y Toulemonde 73)

La perversión en este caso llega también por el relato pagano al inocente que también es el infante. A su vez, en la producción cinematográfica, la imposición de la moral, lengua y religión españolas - por parte de los frailes - a los niños huérfanos de las caucherías resal- ta que la inocencia no se limita a términos etarios, pues dicho suceso determina el carácter de estos sujetos en su edad adulta, volcándolos hacia un fanatismo ideológico en el que se concibe como mesías autoproclamado a un hombre brasileño. Esto, sin duda, conlleva a una pérdida de identidad nativa que a su vez sugiere la emancipación de algunos de estos pueblos:

\section{KARAMAKATE (CONT'D):}

Los curas también me recogieron cuando los caucheros acabaron con mi pueblo. Ellos no se dejaron esclavizar; pelearon. Y así deben ser ustedes. No les crean a estos curas locos

\footnotetext{
Si para Rousseau, en el Emilio o De la educación, es la debilidad característica fundamental de la infancia y es la muerte la condición propia del hombre, pues como el mismo refiere «Es la debilidad del hombre la que lo hace sociable; son nuestras miserias comunes las que llevan nuestros corazones hacia la humanidad, [...] todos han nacido desnudos y pobres, todos sujetos a las miserias de la vida, a los pesares, a los males, a las necesidades, a los dolores de toda clase; en fin, todos estamos condenados a morir» (1998. p. 326). Para algunos pensadores como Walter Benjamín o Giorgio Agamben la infancia es en sí la condición de lo humano, pues es en ella en la que se expone la relación entre experiencia y lenguaje y, por lo tanto, es la infancia del hombre la que posibilita la historia (Vignale, 2009).
} 
que se comen el cuerpo de sus dioses. Ellos les dan comida, pero no respetan las prohibiciones. Un día van a acabar con la selva. (Guerra y Toulemonde 70)

Ahora bien, lo que muestra de manera particular la experiencia cinematográfica es que el relato ya no es solo uno. Como lo resalta Satizábal:

Karamakate y el joven indígena guía del viajero europeo, sentados frente a las cachoeiras o los rápidos sagrados conversan que desde niños aprendieron de sus abuelos las historias de la fundación: los rápidos están escritos con la memoria del mito. (53)

Hay un relato que va hacia el infante desde la tradición y que va más allá de aquella visión casi idílica de una transmisión pura; por el contrario, se pervierte con el relato de los otros, como en el caso del cura Gaspar. En el mismo, encontramos la inocencia-infancia como la condición de la pérdida: «concebida como un sueño, una fantasía, la inocencia, a diferencia de la realidad que prueba su existencia con su dureza, no parece existir más que en el recuerdo de quien se ha hecho adulto» (Sanmartín 140).

Al respecto, afirma Jean-François Lyotard en Lecturas de infancia:

Bauticémosla infantia, lo que no se habla. Una infancia que no es una edad de la vida y que no pasa. Ella puebla el discurso. Éste no cesa de alejarla, es su separación. Pero se obstina, con ello mismo, en constituirla, como pérdida. Sin saberlo, pues, la cobija. Ella es su resto. Si la infancia permanece con ella, es porque habita en el adulto, y no a pesar de eso ( 10).

Será indudablemente la posibilidad del relato, de la relación del indígena con un lenguaje carente de gramática y con una experiencia aún no contada, la que se establece como necesidad tanto en La Vorágine como en El abrazo de la serpiente. Casement señala al respecto que las características que definen al pueblo indígena son aprovechadas por los empresarios y dan cuenta del perpetuo sometimiento al realizar un trato al mismo como se trata al infante: «además, el indio es por naturaleza dócil y obediente. Su debilidad de carácter y docilidad de temperamento no tienen cómo encarar la habilidad de dominación» (caaap y iwgia 51). De esta manera, se define el rasgo indígena que prevalece frente a la barbarie extractivista y que está en relación directa con la inocencia. Dicha característica, a su vez, es resaltada por Rivera:

Los indios encargados de procurarnos la mercancía fueron estafados por los tenderos de Orocué. En cambio de los artículos que llevaron: seje, chinchorros, pendare y plumas, recibieron baratijas que valían mil veces menos. Aunque el Pipa les enseñó cuidadosamente los precios razonables, sucumbieron a su ignorancia y la avilantez de los explotadores volvió a enriquecerse con el engaño ( 150).

Por otro lado, el indígena es percibido por los colonizadores como un ser salvaje, más cercano a un animal que a un hombre, con lo cual se justifica la violencia en la idea de civilización; el desconocimiento y negación de la diferencia de esta idea condena al pueblo indígena a la barbarie. Es así como, las declaraciones de la tan conocida masacre de dieciséis 
indígenas guahibos en 1967, en las que los genocidas alertan con sus declaraciones esta idea del indio salvaje, como lo señala Germán Castro Caycedo, citado por Rueda Enciso: «matar indios no era malo, ni mucho menos un delito, que era como una chanza y que eso no tenía castigo pues eran como animales salvajes, dañinos, que mataban a los otros animales, a las reses» (177). Por su lado, en La Vorágine, Fidel Franco, en una lucha territorial con un grupo indígena, desde su mirada de colono, afirma:

Y para colmo los indios guahibos de las costas del Guanapalo, que flechaban reses por centena- res, asaltaron la fundación del Hatico, llevándose a las mujeres y matando a los hombres. Gracias a que el río detuvo el incendio, pero hasta no sé qué noche, se veía el lejano resplandor de la candela.

— ¿Y qué piensa usted hacer con su fundación? - pregunté.

— ¡Defenderla! Con diez jinetes de vergüenza, bien encarabinados, no dejaremos indio con vida. (Rivera 50)

Se visibiliza, entonces, no sólo la idea errónea que se asume del indígena, sino la lucha que tienen estos pueblos por recuperar los derechos sobre su territorio, que han sido invadidos gracias al desigual enfrentamiento. Es en este punto como, El abrazo de la serpiente enfatiza en ese aspecto: el hombre blanco, en términos de los nativos, representa la extinción para la tribu Cohiuano, quiénes han perecido a causa de la soberbia blanca: «El Maestro caapi será su guía. Nunca olviden quiénes son ni de dónde vienen. No permitan que nuestra canción se extinga» (Guerra y Toulemonde 70). Así mismo, desde la voz de Cova, voz neutral (en ese momento) que se relaciona con la complicidad, se señala la persecución y el asesinato de un grupo indígena, como si estos fueran criaturas salvajes:

De repente, la aulladora jauría, con la nariz en alto, circundó el perímetro de una laguna disimulada por los elevados juncos. Mientras los jinetes corrían haciendo fuego, vi que una tropa de indios se dispersaba entre la maleza, fugándose en cuatro pies, con tan acelerada vaquía que apenas se adivinaba su derrotero por el temblor de los pajonales. Sin gritos ni lamentos las mujeres se dejaban asesinar, y el varón que pretendiera vibrar el arco, caía bajo las balas, apedazado por los molosos (Rivera 123).

Si bien Arturo inicia el re corrido por la selva teniendo como base esta percepción: «los aborígenes del bohío eran mansos, astutos y pusilánimes, se parecían como las frutas de un mismo árbol» (Rivera 143), al finalizar el recorrido y tras continuas transformaciones, resignifica la figura del indígena desde el reconocimiento de su proyecto emancipador. Los relatos de Helí Mesa, Ramiro Estévanez y, especialmente, Clemente Silva contribuirán a dicha transformación, ya que su carencia de proyecto adquiere valor desde diferentes matices: se reconoce en la causa de Silva, de Alicia y su hijo, y por supuesto, en la causa cauchera:

Ay, señor, parece increíble. Son picaduras de sanguijuelas. Por vivir en las ciénagas picando goma, esa maldita plaga nos atosiga, y mientras el cauchero sangra los árboles, las sanguijuelas 
lo sangran a él. La selva se defiende de sus verdugos, y al final el hombre resulta vencido (Rivera 186).

Por ende, se hace vocero de esta última y resalta el afán para que su relato, que contiene los pormenores de dicha tragedia, llegue a las autoridades competentes: «Cuide mucho esos manuscritos y póngalos en manos del Cónsul. Son la historia nuestra, la desolada historia de los caucheros. ¡Cuánta página en blanco, cuánta cosa que no se dijo!» (Rivera 342). El egoísmo que caracteriza al poeta en el comienzo de su travesía se transforma a partir de la empatía con la causa cauchera:

Hizo a los caucheros una promesa de redención, realizable desde la fecha en que alguna mano (ojalá que fuera la mía) esbozara el cuadro de sus miserias y dirigiera la compasión de los pueblos hacia las florestas aterradoras; consoló a las mujeres esclavizadas, recordándoles que sus hijos han de ver la aurora de la libertad que ellas nunca miraron. (Rivera 278)

Asimismo, en El abrazo de la serpiente se redefine el concepto del indígena a través de la relación de Karamakate y Theodor, en el que este último se reconstruye como sujeto a partir del reconocimiento de la realidad indígena, realidad que es contada desde la propia voz de los protagonistas, como lo señala Ciro Guerra en el guión cinematográfico: «los exploradores han contado su historia. Pero los nativos no. Su historia es ésta. Un pedazo de tierra del tamaño de un continente, que no se ha contado» (Guerra y Toulemonde p. iv). De esta manera, los nativos son el reflejo de diversas rupturas $y$, sin embargo, se redefinen para preservar su esencia:

\section{KARAMAKATE:}

Antes de convertirse en guerrero, todo hombre Cohiuano debe dejar todo, e irse solo al monte, guiado solamente por lo que le dicen sus sueños. En ese viaje debe descubrir, en soledad, en silencio, quién es realmente. Debe convertirse en un vagabundo de sueños. Muchos se pierden, algunos nunca vuelven. Pero los que lo hacen, ya están listos para enfrentar todo lo que pueda venir. (Guerra y Toulemonde 97-100)

Así pues, el concepto del pueblo indígena se reconstruye desde el relato cinematográfico en su relación intertextual con el texto literario, en el que se esboza la mirada colona de sus singularidades y se plantea una mirada más acertada de estas: sobresale su organización social, sus creencias espirituales, sus relaciones con lo natural y las contradicciones propias de cada cultura. Esta relación da voz a los que fueron silenciados por mucho tiempo y que, a través de la expresión artística, pueden tener un medio para expresar su percepción, su ruptura y su afán por reconstruir el presente.

\section{A modo de conclusión}

En 2014, el Centro Nacional de Memoria Histórica de Colombia (cnmh) publica un texto denominado Putumayo: la vorágine de las caucherías. Memoria y testimonio. La obra (com- 
puestas por dos tomos) consiste en un inmenso esfuerzo por rescatar muchas de las voces y las memorias, en ocasiones olvidadas o silenciadas, de una región que en sí misma es víctima de múltiples episodios de violencia que aún no terminan. En el segundo tomo aparece el relato que hace un misionero capuchino sobre su exploración a los Witotos, infieles del bajo Caquetá. En un fragmento de este texto, fechado en 1903, se lee:

Lo que más nos desagradó y causó honda impresión fue la desnudez en que viven. Las pobres mujeres andan completamente desnudas; más los hombres llevan ceñida a la cintura una angosta faja de la corteza de un árbol, que le cubre muy apenas. Viven en tal estado, sin el menor rubor, como si tuvieran la inocencia del paraíso terrenal. (cnmh 28)

Aquí la inocencia aparece como un rasgo nuevamente distintivo que desagrada al monje capuchino, a pesar de que la única analogía que puede realizar es la del paraíso terrenal. Quizás esta imagen muestra, a modo de conclusión, la ambivalencia que surge en las múltiples representaciones de lo indígena. En los casos precisos que se ocupa este artículo, se puede pensar que la resignificación de la mirada unívoca que se ha hecho de lo indígena, asociado únicamente a lo salvaje, permite indudablemente pensarnos desde el presente esas prácticas de invisibilización, desde el mismo relato.

La actualización del debate de la cauchería, por parte de Ciro Guerra, hace que se deba revisar desde una mirada crítica cómo se ha representado a lo indígena y las formas en las que, como refiere Sanmartín, los «tullidos, discapacitados, ciegos, obreros de color, gente que vive en medio de una gran depresión económica, de una crisis histórica, o que trata de reproducir un tipo social anterior a la industrialización» (Sanmartín 144) adquieren un lugar visible en el relato. Tal como muestra Alejandra Jaramillo:

La identidad nacional, considerada como un sistema de narrativas cambiantes a través de las cuales los sujetos de una sociedad viven y entienden su realidad, en un contexto de violencia como la colombiana, requiere realizar procesos de comprensión, reparación y resignificación de esta. (Jaramillo 321)

Esta resignificación de la representación de lo indígena abre un nuevo camino para pensar las distintas formas en cómo ciertas categorías más asociadas a lo afectivo, a lo menor y, en general, a la infancia (en contraposición a la mayoría de edad de los ilustrados) permiten releer nuestra literatura.

Tanto La Vorágine como El abrazo de la serpiente y las rutas seguidas por sus personajes hablan de un vasto territorio, con lo cual se establece el valor geográfico e histórico de las mismas, pues no se limita a la actividad cauchera dentro del territorio nacional, sino que se establece una relación con lugares como Iquitos en Perú y Manaos en Brasil. De esta manera, el espacio geográfico de las narraciones revela la magnitud de la problemática y actualiza el debate social y político sobre dichos territorios. De igual forma, su transformación perceptiva nos sugiere una nueva mirada sobre el indígena y la compleja realidad que aún lo define, quizás para encontrarlos aún no devorados por la selva. 


\section{REFERENCIAS}

Alzate,Carolina. Restrepo, Beatriz y Osorio Betty. La escritura, ese lugar que me acompaña. Bogotá: Ediciones Uniandes, 2014.

Benso, Silvia. La vorágine: una novela de relatos. Thesaurus, 25 de noviembre de 2019. Web 30 de enero de 2021.

El Centro Amazónico de Antropología y Aplicación Práctica (CAAAP) y el Grupo Internacional de Trabajo sobre Asuntos Indígenas (IWGIA) Libro Azul Británico - Informes de Roger Casement y otras cartas sobre las atrocidades en el Putumayo. [ebook] 2012. Perú. <https://www.iwgia.org/es/recursos/publicaciones/317-libros/3067-libro-azul-britnico-informes-de-roger-casement-y-otras-cartas-sobre-las-atrocidades-en-el-putumayo.html>

Centro de memoria Histórica. "Putumayo: La Vorágine de Las Caucherías. Memoria y Testimonio. Segunda Parte. 2014 Colombia. https://babel.banrepcultural.org/digital/collection/p17054coll2/id/12/

Chaparro Amaya, Adolfo. Modernidades periféricas: archivos para la historia conceptual de América Latina.(N/A ed.) Herder Editorial, 2020.

Rueda Enciso, José Eduardo. Alianza y conflicto interracial en los Llanos de Casanare (Virreinato del Nuevo Reino de Granada). El caso del adelantado Juan Francisco Parales, 1795-1806. (2011): 176-208. Web. 27 de marzo.2021. https://doi. org/10.22380/2027468878

Espósito, Roberto. Tercera persona. Política de la vida y filosofía de lo impersonal. Buenos Aires: Amorrortu, 2009a.

Comunidad, inmunidad y biopolítica. Trad. Alicia García Ruiz. Bar- celona: Herder Editorial. 2009b

[Material audiovisual] Contra-pedagogías de la crueldad. Rita Segato. Facultad libre, 2016. Web.https://www.youtube.com/ watch?v=17ijWDlok2g\&t=1411s

Guerrra, Ciro y Toulemonde, Jacques. El abrazo de la serpiente. (2016): Guiones Núm. 6. Web. 12 de julio. 202.0 https://cinema23.com/wp-content/uploads/2016/07

Jaramillo, Alejandra. Nación y melancolía: literatura de la violencia en Colombia, 1995 2005. (2007): Arbor. Ciencia, Pensamiento y Cultura,319-330. Impreso. 
Lyotard, Jean Francois. Lecturas de infancia: Joyce, Kafka, Sartre, Válery, Freud . Buenos Aires: Eudeba, 1997.

Marín, Alejandra. Filosofía venidera e infancia: una comunidad siempre por venir. (2011): 1-17. Web. Recuperado de https://www.javeriana.edu.co/cuadrantephi/pdfs/N.22/1. pdf

Marín Baena, Ricardo Antonio. Abrasándonos en el Abrazo de la Serpiente. Esbozo ensayístico acerca de la película colombiana «El abrazo de la serpiente», dirigida por Ciro Guerra Revista Científica General José María Córdova, 14(2016): 454-458. Impreso

Orrego Arismendi, Juan Carlos. La crítica de la novela indigenista colombiana: objetos y problemas. Estudios de Literatura Colombiana . (2012): 31-54. Web. https:// revistas. udea.edu.co/index.php/elc/article/view/12979

Rivera, José Eustasio. La Vorágine. Bogotá: Ministerio de Cultura, 2015. Recuperado de https://siise.bibliotecanacional.gov.co/BBCC/Documents/Doc/209?AspxAutoDetectCookieSu- pport=1.

Rousseau, Jean-Jacques. Emilio o De la educación. Madrid: Alianza Editorial.

Sanmartin, Ricardo. Libertad, sensualidad e inocencia: ensayos en antropología del arte II. Madrid: Editorial Trotta. 2011

Satizabal, Carlos. El abrazo de la serpiente o la poesía del viaje sagrado. (2016):53-65.Web. Recuperado de http://www.uartes.edu.ec/fueradecampo/?p=31

Uscátegui Nárvaes, Alexis. Finales para Aluna de Selnich Vivas Hurtado: decapitación, máscaras y el polvo ínfimo del cuerpo amazónico. (2017): 227-242. Web. Recuperado de https://revistas.uptc.edu.co/index.php/la_palabra/article/view/7269/6016

Vignale, Silvana. Infancia y experiencia en Walter Benjamin: Jugar a ser otro. Childhood \& Philosophy (2009): 77-101 Web. 21 de Febrero . 2021. https://www.redalyc.org/ articulo. oa? $\mathrm{id}=5120 / 512051710008$ 